\title{
Adsorption Mechanism of Ciprofloxacin from Water by Synthesized Birnessite
}

\author{
Xuebing Xing, ${ }^{1}$ Jingwen Feng, ${ }^{1}$ Guocheng Lv, ${ }^{1}$ Kenan Song, ${ }^{2}$ Lefu Mei, \\ Libing Liao, ${ }^{1}$ Xiaoyu Wang, ${ }^{1}$ and Ben $\mathrm{Xu}^{2}$ \\ ${ }^{1}$ Beijing Key Laboratory of Nonmetallic Minerals and Material Utilization of Solid Wastes, School of Material Sciences and Technology, \\ China University of Geosciences, Beijing 100083, China \\ ${ }^{2}$ School of Materials Science and Engineering, Tsinghua University, Beijing 100084, China
}

Correspondence should be addressed to Guocheng Lv; guochenglv@cugb.edu.cn and Ben Xu; xu9ben@gmail.com

Received 11 August 2014; Revised 14 September 2014; Accepted 15 September 2014

Academic Editor: Zhaohui Li

Copyright (C) 2015 Xuebing Xing et al. This is an open access article distributed under the Creative Commons Attribution License, which permits unrestricted use, distribution, and reproduction in any medium, provided the original work is properly cited.

\begin{abstract}
The efficiency of ciprofloxacin (CIP) adsorption on synthesized birnessite was systematically studied under varying physicochemical conditions, such as solution $\mathrm{pH}$, contact time, initial CIP concentration, and different average oxidation states (AOS) of Mn in birnessite. X-ray diffraction (XRD), Fourier transform infrared (FTIR), and molecular simulations were employed to investigate the adsorption mechanism of CIP on birnessite. Experimental results showed that surface adsorption instead of cation exchange was responsible for the uptake of CIP on birnessite. The quantum mechanics simulation showed that the final energy of the interaction between CIP and birnessite was smaller under the condition when the AOS of Mn was lower, in comparison to the case when the AOS of Mn was high. The highest CIP adsorption occurred under a weak alkaline condition.
\end{abstract}

\section{Introduction}

Antibiotics refer to a group of substances that can effectively inhibit growth of pathogens or other active materials. Since Alexander Fleming discovered penicillin in 1928, a large number of antibiotics are not only used to treat human and animal diseases but also widely used in poultry feeding and aquaculture. Antibiotics play an important role in preventing disease and promoting growth [1]. Many antibiotics have the characteristics of low biodegradability and are persistent in the environment [2].

Nonbiodegradable quinolone antibiotics are an important type in the commonly used antibiotics. The most extensively used prescribed quinolone antibiotic is ciprofloxacin that can effectively act against a wide range of gram-negative and gram-positive bacteria. In addition, CIP has high water solubility under different $\mathrm{pH}$ conditions and has stability in soil and wastewater [3-7]. It can be removed by wastewater treatment, owing to its significant adsorption onto the sludge floc [3]. Although $90 \%$ of CIP could be removed by activated carbon from sludge [4], it is still found in the effluent of sewage treatment plants. Studies of the interaction between these pollutants and soil or sediment have attracted great attention as more and more antibiotics are detected in surface and wastewater.

Birnessite was originally thought as the air oxidation product of manganese oxide in alkaline conditions in Scotland [8]. It is one of the most common manganese oxides in soil and is also a potential, yet efficient, adsorbent [9]. It has an octahedral layered structure and a large specific surface area $\left(63-300 \mathrm{~m}^{2} \mathrm{~g}^{-1}\right)$ [10]. The charge of $\mathrm{Mn}$ in octahedral sites varies with the changes of environment and leads to different number of interlayer cations [11]. The interlayer cations can be more easily replaced by other inorganic or organic cations based on the electronegative level [12]. The sodium ions in birnessite can be fully exchanged by univalent ions and partly exchanged by calcium and magnesium ions [13]. Some recent studies reported that birnessite was able to promote the decomposition of tetracycline or CIP [14-17].

The aim of this study was to study CIP adsorption on birnessite under different physicochemical conditions and to investigate the potential mechanism of CIP adsorption on 


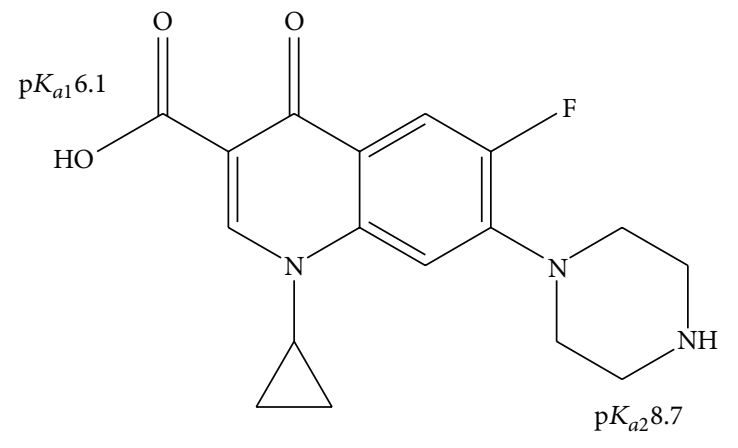

(a)

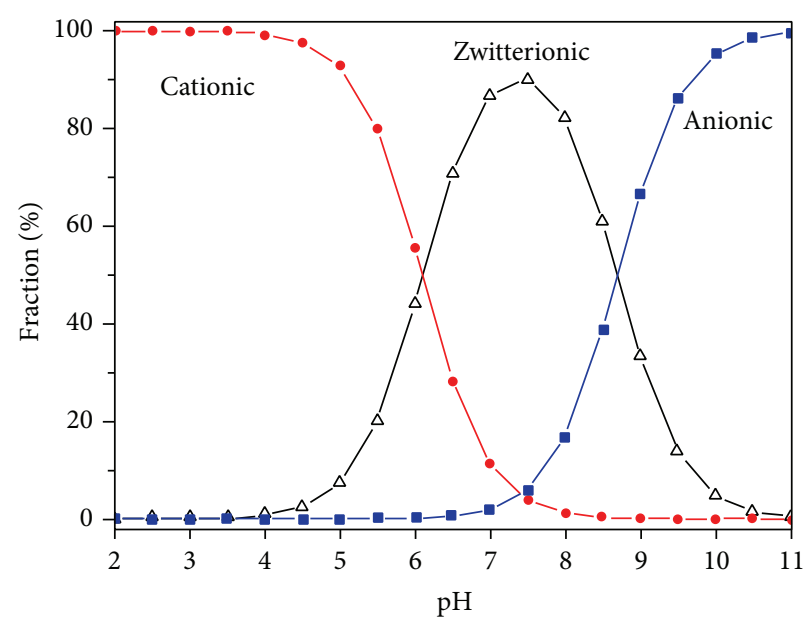

(b)

FIGURE 1: Molecular structure of ciprofloxacin (a) and speciation of CIP as a function of solution pH (b).

birnessite using X-ray diffraction (XRD), Fourier transform infrared spectroscopy (FTIR), and Material Studio simulation.

\section{Materials and Methods}

2.1. Experimental Materials. Sodium hydroxide, manganese chloride $\left(\mathrm{MnCl}_{2} \cdot 4 \mathrm{H}_{2} \mathrm{O}\right)$, and potassium permanganate were all purchased from Beijing Chemical Works. CIP has a water solubility of $30 \mathrm{~g} / \mathrm{L}$ at $20^{\circ} \mathrm{C}$ and acid dissociation constants $\mathrm{p} K_{a 1}$ and $\mathrm{p} K_{a 2}$ at 6.1 and 8.7 [18]. When the $\mathrm{pH}$ is less than 6.1, the CIP molecule exists as a cation because of the protonation of amino in the triazine part. Between $\mathrm{pH} 6.1$ and 8.7, zwitterion is the main form of CIP due to protonation of amino in the piperazine part and deprotonation of carboxyl. An anion is a dominant species when $\mathrm{pH}$ is greater than 8.7, as a result of the loss of amino group proton in piperazine moiety [19] (Figure 1).

\subsection{Preparation of Birnessite with Different Average Oxidation} States (AOS) of $\mathrm{Mn}$. In this paper, a liquid-phase reaction method was used to prepare birnessite. The first step was to mix $0.02 \mathrm{~mol} \mathrm{MnCl}_{2} \cdot 4 \mathrm{H}_{2} \mathrm{O}$ and $0.25 \mathrm{~mol} \mathrm{NaOH}$ in $100 \mathrm{~mL}$ distilled water. In order to form a homogeneous solution, the mixture was stirred for $1 \mathrm{~min}$ at room temperature. And then solution was mixed with $50 \mathrm{~mL} \mathrm{KMnO}_{4}$ solution in different molar ratio $(61.76 \%, 57.89 \%, 54.76 \%, 52.17 \%, 50.00 \%$, and $48.15 \%$ ) relative to $\mathrm{MnCl}_{2} \cdot 4 \mathrm{H}_{2} \mathrm{O}$ and stirring continued for $30 \mathrm{~min}$ to insure the reaction was complete. The product was aged for $24 \mathrm{~h}$ at room temperature. At last, the products were washed with distilled water for ten times and dried at $60^{\circ} \mathrm{C}$ for $24 \mathrm{~h}$. Then series of birnessites with different AOS of Mn were obtained, named (I, II, III, IV, V, VI).

2.3. CIP Adsorption on Birnessite. Kinetics of CIP adsorption were carried out to evaluate the parameters of CIP removal from water by birnessite and to provide guides for further studies on equilibrium CIP adsorption and effect of solution $\mathrm{pH}$ on CIP adsorption.

The study of the kinetics of CIP adsorption on birnessite was performed by mixing $0.1 \mathrm{~g}$ dry weight of birnessite with $25 \mathrm{~mL}$ of $1000 \mathrm{mg} / \mathrm{L} \mathrm{CIP}$ solution on a horizontal shaker at $150 \mathrm{rpm}$ for the following shaking times: $0.5,1,2,10,20,30$, $60,120,180,240$, and 300 min.

For CIP adsorption isotherm study, $0.1 \mathrm{~g}$ (dry weight) of birnessite was mixed with $10 \mathrm{~mL}$ CIP solution in each $50 \mathrm{~mL}$ centrifuge tube at initial concentrations of 500, 1000, 2000, 3000,4000 , and $6000 \mathrm{mg} / \mathrm{L}$ on a horizontal shaker at $150 \mathrm{rpm}$ for $24 \mathrm{~h}$.

The $\mathrm{pH}$ of the equilibrium solution was kept about 6.4 for the kinetics and isotherm study.

For the study of influence of solution $\mathrm{pH}$ on CIP adsorption, $0.1 \mathrm{~g}$ (dry weight) of birnessite and $25 \mathrm{~mL}$ of $2000 \mathrm{mg} / \mathrm{L}$ CIP solution were mixed in each $50 \mathrm{~mL}$ centrifuge tube. Then, solution $\mathrm{pH}$ was measured and readjusted with $\mathrm{HCl}$ or $\mathrm{NaOH}$ every $8 \mathrm{~h}$ until the $\mathrm{pH}$ stabilized at the desired final solution $\mathrm{pH}$ of 1-11 with an increment of 2 . The total time of mixing was $24 \mathrm{~h}$.

For the three experiments mentioned above, a duplicate was performed for each variable. After desired time, the mixture was centrifuged for $10 \mathrm{~min}$ at $7500 \mathrm{rpm}$ and the supernatant passed through $0.45 \mu \mathrm{m}$ syringe filters before being analyzed for equilibrium CIP concentrations using a UV-Vis method.

All experiments mentioned above were carried out to provide guidance for the following experiment: the effect of AOS of $\mathrm{Mn}$ in birnessites (different molar ratio of $\mathrm{KMnO}_{4}$ and $\mathrm{MnCl}_{2} \cdot 4 \mathrm{H}_{2} \mathrm{O}$ ) on CIP adsorption. $0.1 \mathrm{~g}$ dry weight of different kind of birnessite and $25 \mathrm{~mL}$ of $6000 \mathrm{mg} / \mathrm{L}$ CIP solution were mixed in each $50 \mathrm{~mL}$ centrifuge tube under the conditions of $\mathrm{pH}=7$.

2.4. Methods of Analyses. We determined the equilibrium CIP concentrations via a UV-Vis spectrophotometer at the wavelength of $280 \mathrm{~nm}$; the calibration curve was established 


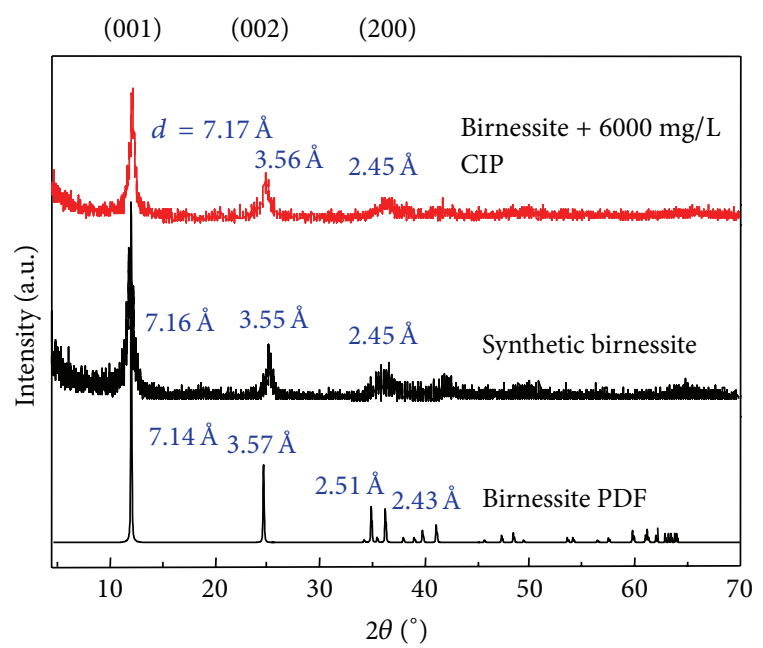

FIGURE 2: X-ray diffraction patterns of birnessite (V) and birnessite (V) which was reacted with the concentration of $6000 \mathrm{mg} / \mathrm{L} \mathrm{CIP}$ solution.

by 10 standards in the range of $1-10 \mathrm{mg} / \mathrm{L}$ and the coefficient of regression $r^{2}$ was 0.997 . For the experiment of influence of solution $\mathrm{pH}$ on CIP adsorption especially, we established 6 calibration curves with the $\mathrm{pH}$ of $1,3,5,7,9$, and 11 to determine the equilibrium CIP concentrations.

For the crystal structure of manganese dioxides, X-ray powder diffraction analysis was used to characterize it. And it was performed at $40 \mathrm{kV}$ and $100 \mathrm{~mA}$. Oriented samples were scanned from $2 \theta 3^{\circ}$ to $70^{\circ}$ with a scanning speed of $8^{\circ} / \mathrm{min}$.

The FTIR spectra were collected by accumulating 16 scans at a resolution of $4 \mathrm{~cm}^{-1}$ in the range of 450 to $4000 \mathrm{~cm}^{-1}$ on a Spectrum 100 spectrometer equipped with a mercury cadmium telluride detector.

Molecular simulation of binding energy between birnessite of different AOS of Mn and CIP was studied by means of the module Forcite of Materials Studio 5.0 software. During simulation, the quantum chemical module of Materials Studio CASTEP was used to calculate the interaction energy between CIP and birnessite. By comparing the energies, the ease of interaction between CIP and birnessite on edge surface could be determined. The lower the energy is, the more easy the interaction is.

Birnessite is a layered manganese oxide mineral. Each layer consists of edge-shared $\mathrm{MnO}_{6}$ octahedron. In the interlayer space, there are metal cations and water molecules. The birnessite model was constructed and the atomic coordinates were derived from the space group of $\mathrm{C} 1$ with $a=5.175 \AA$, $b=8.93 \AA, c=7.38 \AA$, and $\beta=103.18^{\circ}$ [20]. And we chose the (010) plane of birnessite as a demonstrational edge surface and (001) plane as the basic surface in this study.

\section{Results and Discussion}

3.1. Characterization of Birnessite (V) by XRD. The original sample of birnessite $(\mathrm{V})$ and the birnessite $(\mathrm{V})$ reacted with the concentration of $6000 \mathrm{mg} / \mathrm{L}$ CIP solution were characterized by XRD (Figure 2). The results showed that

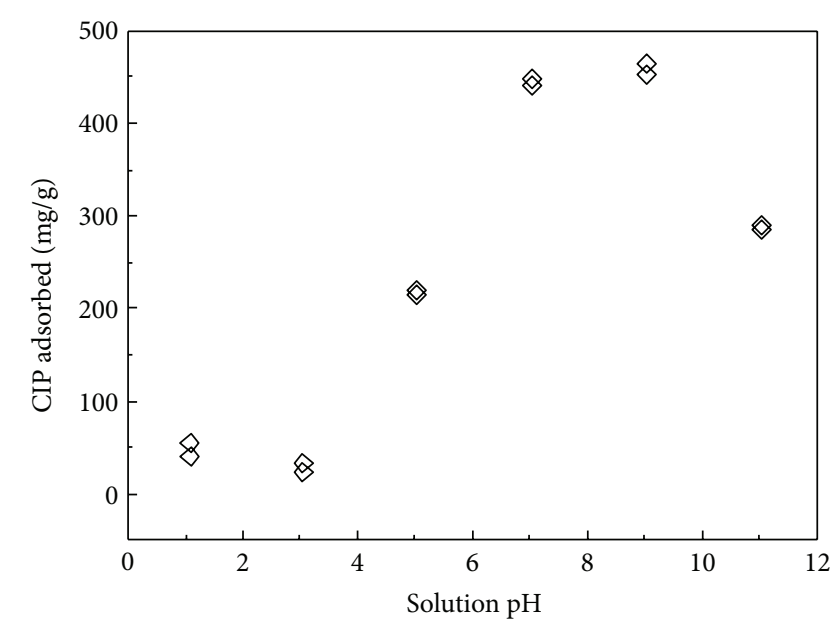

FIgUre 3: Adsorption of CIP on birnessite (V) affected by solution $\mathrm{pH}$.

the synthetic material agreed well with the standard cards of birnessite, indicating that the synthetic material was relatively pure birnessite. On the other hand, compared with the two XRD diffraction patterns, the corresponding peak of (001) crystal planes was not moved and the layer spacing remained the same, proving that surface adsorption instead of interlayer adsorption was the main form of CIP uptake on birnessite.

3.2. Influence of Solution $p H$ on CIP Removal by Birnessite. The electric charges of CIP vary with $\mathrm{pH}$ and lead to different CIP adsorption capacity. Under strong acidic conditions, changes in solution $\mathrm{pH}$ had a minimal effect on CIP removal. And then CIP adsorption increased gradually with the increase of $\mathrm{pH}$. Above $\mathrm{pH}$ 8.7, a further increase in solution $\mathrm{pH}$ resulted in a remarkable decrease in CIP removal (Figure 3). This trend was similar to CIP adsorption on Camontmorillonite and kaolinite [21, 22].

Considering that the $\mathrm{p} K_{a}$ values of CIP were 6.1 and 8.7, the CIP was in its zwitterionic form when solution $\mathrm{pH}$ was between 6.1 and 8.7. Even though the net charge of the whole molecule was zero, the positively charged amino was still able to contribute to the adsorption of CIP on birnessite. Therefore, a higher adsorption capacity occurred in the range of $\mathrm{pH} 3$ to 8.7. The adsorption was lower when solution $\mathrm{pH}$ was 3 or less, because the negative charge of birnessite surface decreased under low $\mathrm{pH}$ [27] and brought repulsion with the positively charged CIP. When solution $\mathrm{pH}$ was greater than 8.7, an anion played a dominant role in CIP speciation. Significant repulsion was induced between the negatively charged surfaces of birnessite and CIP. Thus CIP removal on birnessite was significantly reduced in this case.

3.3. Kinetics of CIP Removal by Birnessite. The fast adsorption rate was observed in this experiment, and it could reach the adsorption equilibrium in $240 \mathrm{~min}$ (Figure 4), proving that the shaking time of $24 \mathrm{~h}$ was enough for other experiments. Kinetic characteristics of CIP removal agreed well with 


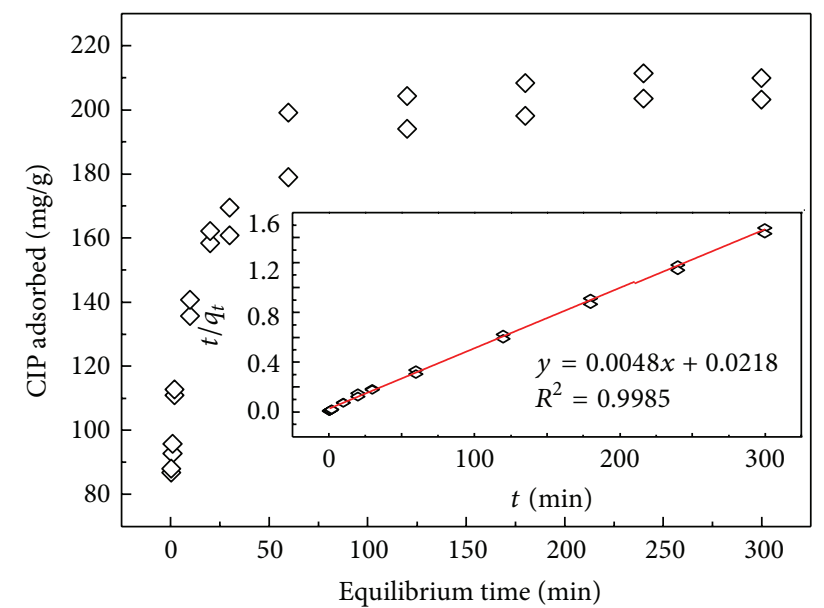

FIgURE 4: Kinetics of CIP adsorption on birnessite (V). The solid line is pseudo-second-order fit to the observed data. Inserts are plot of $t / q_{t}$ against $t$ for birnessite $(\mathrm{V})$.

the pseudo-second-order model. The integrated rate laws of the pseudo-second-order kinetics are $[23,24]$

$$
\begin{aligned}
\frac{t}{q_{t}} & =\frac{1}{K_{s} q_{e}^{2}}+\frac{1}{q_{e}} t, \\
q_{t} & =\frac{C_{0}-C_{t}}{M} V,
\end{aligned}
$$

in which $t(\mathrm{~min})$ is the time of adsorption, $q_{t}(\mathrm{mg} / \mathrm{g})$ is the amount of solute adsorbed on the adsorbent surface at time $t, q_{e}(\mathrm{mg} / \mathrm{g})$ is the amount of solute adsorbed at equilibrium, $K_{S}\{\mathrm{mg} /(\mathrm{g} \cdot \mathrm{min})\}$ is the rate constant for adsorption, and $C_{t}$ and $C_{0}$ are the concentrations of solute at time $t$ and time zero.

The calculated $q_{e}$ was $208 \mathrm{mg} / \mathrm{g}$ close to the experimental value of $203 \mathrm{mg} / \mathrm{g}$. The pseudo-second-order kinetics with a coefficient of correlation $r^{2}=0.999$.

3.4. Equilibrium of CIP Removal by Birnessite. The equilibrium of CIP removal was described by the adsorption isotherm. The observed CIP adsorption capacity was about $419-442 \mathrm{mg} / \mathrm{g}$ at room temperature and the adsorption data was fitted to the Langmuir isotherm (Figure 5).

The linear forms of Langmuir isotherm model can be represented as follows:

$$
\frac{C_{e}}{q_{e}}=\frac{C_{e}}{q_{m}}+\frac{1}{q_{m} K_{L}},
$$

in which $C_{e}$ is the concentration of CIP at equilibrium $(\mathrm{mg} / \mathrm{L}) ; q_{e}$ is the amount of CIP adsorbed per gram of birnessite $(\mathrm{mg} / \mathrm{g}) ; q_{m}$ is the maximum adsorption in theory; and $K_{L}$ is the constant of isotherm equation.

The calculated $q_{m}$ was $455 \mathrm{mg} / \mathrm{g}$ close to the experimental value of $442 \mathrm{mg} / \mathrm{g}$. And the $r^{2}$ of pseudo-second-order kinetics was greater than 0.99 .

The analysis suggested that the thermodynamic characteristics of CIP adsorption were well fitted to the Langmuir model.

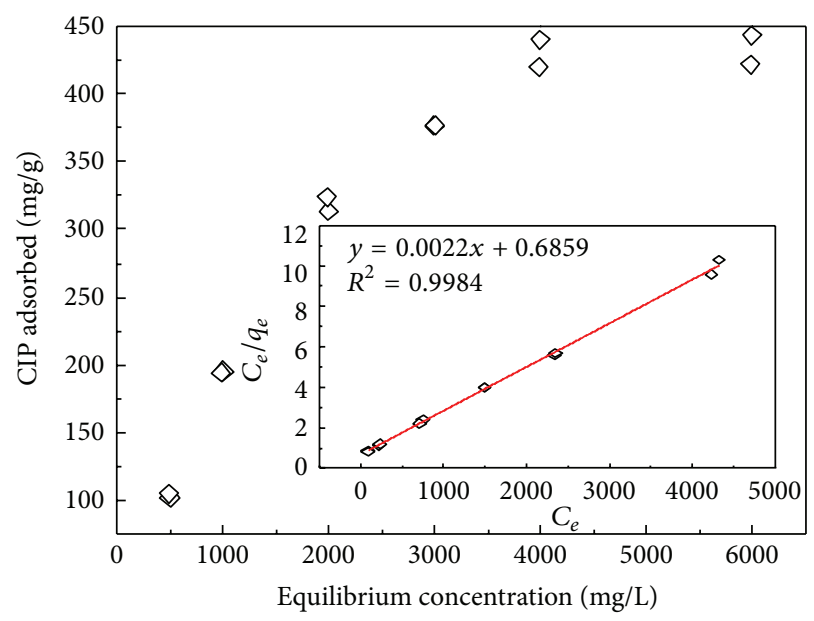

Figure 5: CIP adsorption on birnessite (V). The solid line is the Langmuir fits to the observed data.

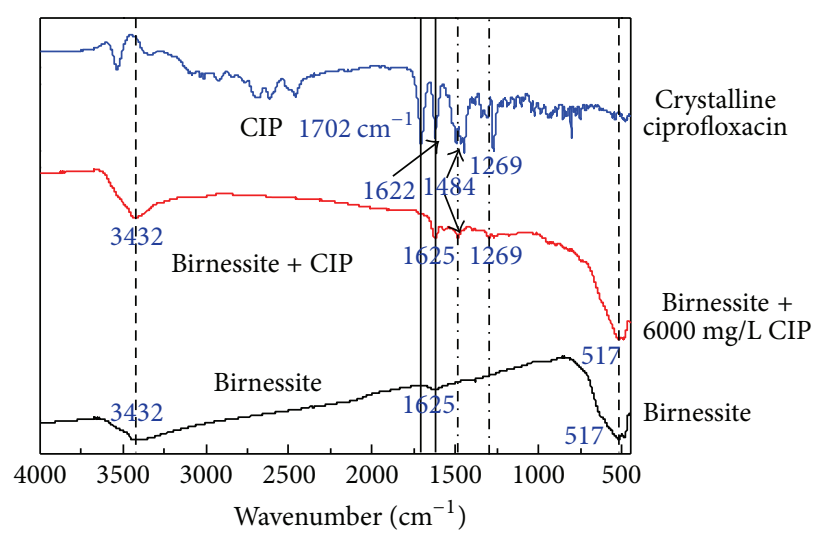

FIGURE 6: FTIR spectra of CIP (6000 mg/L) adsorbed birnessite (V) at $450-4000 \mathrm{~cm}^{-1}$.

3.5. FTIR Analyses. Figure 6 presents the FTIR spectra of CIP, raw birnessite, and $6000 \mathrm{mg} / \mathrm{L}$ CIP adsorbed birnessite.

Compared with the FTIR spectra of raw birnessite and birnessite with absorbed CIP, there was no significant change in the vibration of the backbone of birnessite before and after CIP adsorption, which indicated that the adsorbed CIP did not alter the structure, consistent with XRD observation.

Crystalline CIP had many characteristic peaks at the finger print $\left(1200-1800 \mathrm{~cm}^{-1}\right)$. There was a peak that appeared in $1703-1699 \mathrm{~cm}^{-1}$ due to the fact that the $v$ (carboxylic acid $\mathrm{C}=\mathrm{O}$ ) and the $\nu$ (Ketone $\mathrm{C}=\mathrm{O}$ ) were located at $1622 \mathrm{~cm}^{-1}[18$, 25]. And two relatively strong peaks appeared in $1269 \mathrm{~cm}^{-1}$ and $1484 \mathrm{~cm}^{-1}$.

Because of $\mathrm{MnO}_{6}$ octahedral, the FTIR spectra of original and CIP-absorbed birnessite had a strong absorption peak at about $520 \mathrm{~cm}^{-1}$. A broad weak and a strong broad peaks appeared in 1624 and $3431 \mathrm{~cm}^{-1}$ with the former attributed to less ordered water and the latter to $\mathrm{OH}, \mathrm{H}_{2} \mathrm{O}$ adsorbed on birnessite [26]. The other explanation of these phenomena was the bending mode of $\mathrm{H}_{2} \mathrm{O}$ and the stretching mode of the $\mathrm{OH}$ groups. 


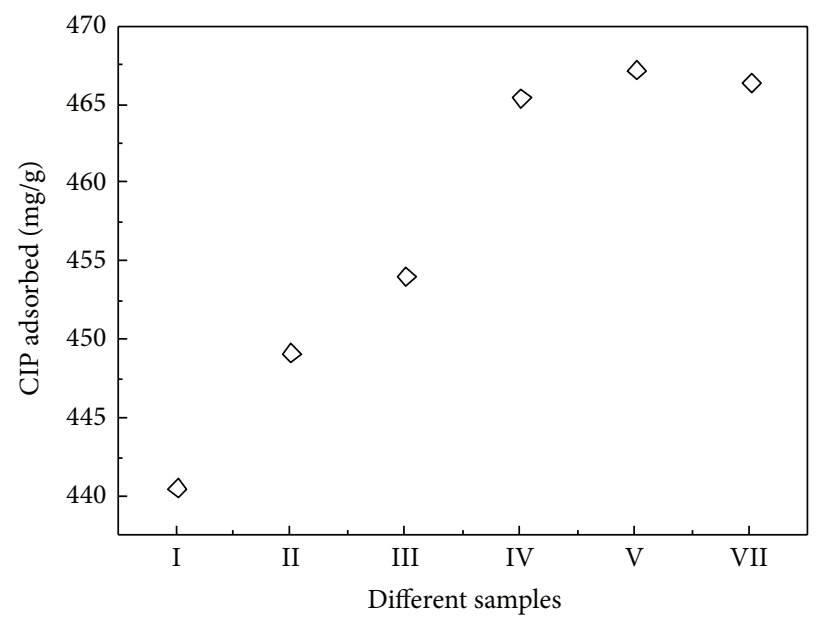

FIGURE 7: CIP adsorption on birnessite samples of different $\mathrm{MnCl}_{2} / \mathrm{KMnO}_{4}$ ratios.

The most obvious changes are those in $1200-1500 \mathrm{~cm}^{-1}$. At wave numbers $1269 \mathrm{~cm}^{-1}$ and $1484 \mathrm{~cm}^{-1}$, which were the characteristic peaks of crystalline CIP, the CIP-absorbed birnessite showed the two new peaks compared with the original material, characterizing the reaction between birnessite and CIP.

3.6. Influence of Birnessite with Different AOS on CIP Removal. Based on the study of influence of solution $\mathrm{pH}$ on CIP removal by birnessite, we chose the same acidity condition $(\mathrm{pH}=7)$ to carry out this experiment.

Adsorption capacity of CIP increased gradually with the increase of the molar ratio of $\mathrm{MnCl}_{2}$ and $\mathrm{KMnO}_{4}$ (Figure 7). Consider that birnessite has a hexagonal symmetry layer structure and may possess a variable number of octahedral cationic vacancies within its layers. Manganese oxide octahedral vacancies lead to the production of the negative charge on the birnessite surface [27]. When solution $\mathrm{pH}$ was 7, part of the CIP was in its cationic form. And the interaction between $\mathrm{CIPH}^{+}$and negative surface charge resulted in the adsorption of CIP on birnessite. The increase of the ratio of $\mathrm{MnCl}_{2}$ and $\mathrm{KMnO}_{4}$ leads to the decrease of $\mathrm{Mn}$ AOS and the increase of surface electronegativity in birnessite. Thus the adsorption capacity of CIP increased from sample I to V.

3.7. Molecular Simulation. As birnessite had two-dimensional morphology microscopically, it could be presumed that the large and flat surfaces on the basic plane would be the sites for adsorption of CIP. And the charge of birnessite is deeply dependent on the ratio of Mn (II) to Mn (VII). If the adsorption of CIP on birnessite was from electrostatic interaction, the location of charge on birnessite would play an important role on the sorption sites of CIP.

We simulated the interactions between CIP and birnessite on (010) surfaces under 3 different conditions for AOS of Mn (Figure 8). To judge which condition is more stable, we calculate the total energy of the 3 different conditions for AOS of Mn. After that, we set the total energy of the highest AOS of $\mathrm{Mn}\left(n\left(\mathrm{KMnO}_{4}\right): n\left(\mathrm{MnCl}_{2}\right)=61.76 \%\right)$ as the standard; when the ratio of $\mathrm{KMnO}_{4}$ to $\mathrm{MnCl}_{2}$ was in sequence of $54.76 \%$ and $50.00 \%$, the differences between the 2 energy values and the standard were in order of -6.55 and $-7.47 \mathrm{KJ} / \mathrm{mol}$. With the increase of the ratio of $\mathrm{Mn}$ (II) to Mn (VII), the difference of total interaction energy decreased more, showing that the system was more stable and leads to higher adsorption capacity of CIP.

The simulations showed that CIP could interact with the (010) edge surfaces more easily under a lower AOS of $\mathrm{Mn}$ due to the comparison among the final energy. And the simulation results agreed well with the experimental phenomenon about birnessite with different AOS on CIP removal.

3.8. Discussion. Because the $\mathrm{pH}$ of the equilibrium solution was 6.4, under which CIP would be a monovalent cation $\mathrm{CIPH}^{+}$. And the birnessite edge would be negatively charged. Therefore, the interaction between birnessite and CIP may cause CIP adsorption by birnessite.

We used Material Studio to simulate CIP removal by birnessite of different AOS of Mn and calculate the binding energy between birnessite and CIP. Quantum mechanics simulation under different proportions of $\mathrm{Mn}^{2+}$ conditions showed that CIP could interact with the (010) edge surfaces more securely when the AOS of Mn decreased, in which case the total negative charges of birnessite increased. This phenomenon suggested again that the removal of CIP by birnessite was due to surface adsorption and it was similar to the adsorption of oxytetracycline on montmorillonite, which confirmed that the dominant mechanism of interaction was the hydrogen bonding [28].

\section{Conclusions}

Kinetic and thermodynamics experiments showed that CIP adsorption fitted to the pseudo-second-order kinetics and Langmuir isotherm model well. We carried out another two experiments of changing the electric charge of CIP (the $\mathrm{pH}$ experiment) and the charge of birnessite (the experiment 


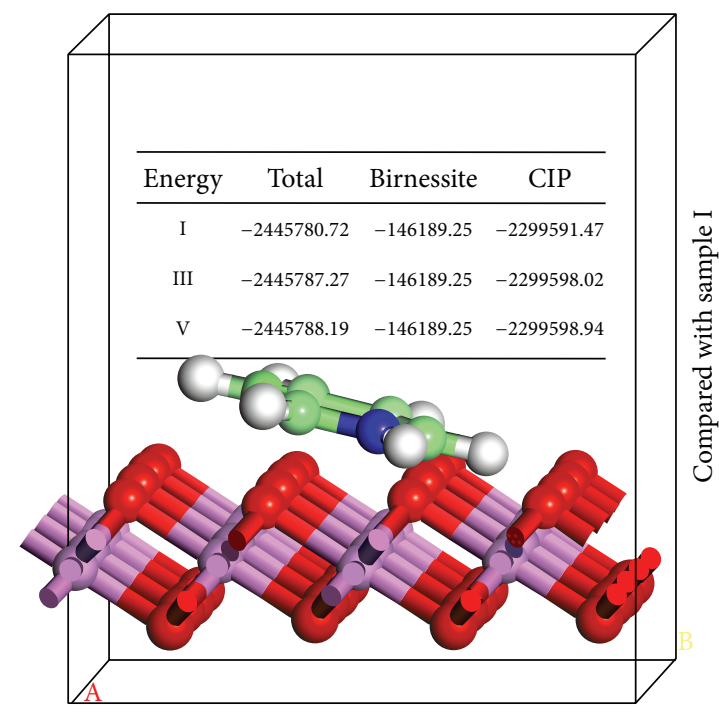

(a)

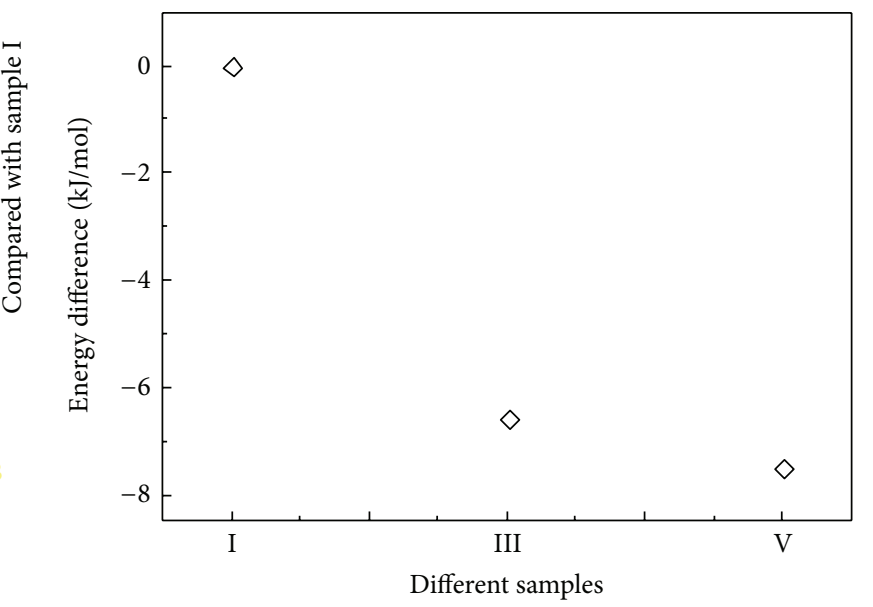

(b)

FIGURE 8: Energy (KJ/mol) of birnessite and CIP in the system of different samples (a) and energy difference compared with the energy of sample I (b).

using birnessite of different AOS of $\mathrm{Mn}$ ), and the results showed that CIP adsorption changed as the electric charge of CIP and birnessite changed. This phenomenon proved that it was surface adsorption that caused the removal of CIP on birnessite. And the XRD, FTIR analysis, and molecular simulations confirmed this mechanism again.

\section{Conflict of Interests}

The authors declare that there is no conflict of interests regarding the publication of this paper.

\section{Authors' Contribution}

Xuebing Xing and Jingwen Feng contributed equally to this paper.

\section{Acknowledgments}

This research was jointly funded by Beijing Higher Education Young Elite Teacher Project, the University Students' Innovative Undertaking Training Program, and International S\&T Cooperation (no. S2014ZR0062).

\section{References}

[1] M. Min and G. Lu, "Antibiotics in the water environment," Chemical and Biological Engineering, vol. 30, no. 11, pp. 19-22, 2013.

[2] J. Kagle, A. W. Porter, R. W. Murdoch, G. Rivera-Cancel, and A. G. Hay, "Chapter 3 biodegradation of pharmaceutical and personal care products," Advances in Applied Microbiology, vol. 67, pp. 65-108, 2009.
[3] E. M. Golet, I. Xifra, H. Siegrist, A. C. Alder, and W. Giger, "Environmental exposure assessment of fluoroquinolone antibacterial agents from sewage to soil," Environmental Science \& Technology, vol. 37, no. 15, pp. 3243-3249, 2003.

[4] X. Yang, R. C. Flowers, H. S. Weinberg, and P. C. Singer, "Occurrence and removal of pharmaceuticals and personal care products (PPCPs) in an advanced wastewater reclamation plant," Water Research, vol. 45, no. 16, pp. 5218-5228, 2011.

[5] C. Miège, J. M. Choubert, L. Ribeiro, M. Eusèbe, and M. Coquery, "Fate of pharmaceuticals and personal care products in wastewater treatment plants-conception of a database and first results," Environmental Pollution, vol. 157, no. 5, pp. 1721$1726,2009$.

[6] A. J. Carrasquillo, G. L. Bruland, A. A. Mackay, and D. Vasudevan, "Sorption of ciprofloxacin and oxytetracycline zwitterions to soils and soil minerals: influence of compound structure," Environmental Science and Technology, vol. 42, no. 20, pp. 7634$7642,2008$.

[7] D. Vasudevan, G. L. Bruland, B. S. Torrance, V. G. Upchurch, and A. A. MacKay, "pH-dependent ciprofloxacin sorption to soils: Interaction mechanisms and soil factors influencing sorption," Geoderma, vol. 151, no. 3-4, pp. 68-76, 2009.

[8] L. H. P. Jones and A. A. Milne, "Birnessite: a new manganese oxide mineral from Aberdeenshire, Scotland," Mineral Magazine, vol. 151, pp. 283-288, 1956.

[9] R. M. McKenzie, "The manganese oxides and hydroxides," in Minerals in Soil Environments, J. B. Dixon and S. W. Weeds, Eds., pp. 439-465, Soil Science Society of American Madison, Madison, Wis, USA, 1989.

[10] J. A. Davis and D. B. Kent, "Surface complexation modelling in aqueous geochemistry," Reviews in Mineralogy, vol. 23, no. 1, pp. $177-260,1990$

[11] J. E. Post and D. R. Veblen, "Crystal structure determinations of synthetic sodium, magnesium, and potassium birnessite using 
TEM and the Rietveld method," American Mineralogist, vol. 75, no. 5-6, pp. 477-489, 1990.

[12] L. Zhao, Y. Sun, and L. Yu, "The organic montmorillonite intercalated modified and performance study," China Mining, vol. 19, no. 11, pp. 1101-1204, 2010.

[13] L. Al-Attar and A. Dyer, "Ion exchange in bimessite," Land Contamination and Reclamation, vol. 15, no. 4, pp. 427-436, 2007.

[14] H. Zhang and C.-H. Huang, "Oxidative transformation of fluoroquinolone antibacterial agents and structurally related amines by manganese oxide," Environmental Science and Technology, vol. 39, no. 12, pp. 4474-4483, 2005.

[15] K. F. Rubert IV and J. A. Pedersen, "Kinetics of oxytetracycline reaction with a hydrous manganese oxide," Environmental Science and Technology, vol. 40, no. 23, pp. 7216-7221, 2006.

[16] W.-R. Chen and C.-H. Huang, "Transformation kinetics and pathways of tetracycline antibiotics with manganese oxide," Environmental Pollution, vol. 159, no. 5, pp. 1092-1100, 2011.

[17] G. Chen, L. Zhao, and Y. H. Dong, "Oxidative degradation kinetics and products of chlortetracycline by manganese dioxide," Journal of Hazardous Materials, vol. 193, pp. 128-138, 2011.

[18] C. Gu and K. G. Karthikeyan, "Sorption of the antimicrobial ciprofloxacin to aluminum and iron hydrous oxides," Environmental Science and Technology, vol. 39, no. 23, pp. 9166-9173, 2005.

[19] C.-J. Wang, Z. Li, and W.-T. Jiang, "Adsorption of ciprofloxacin on 2:1 dioctahedral clay minerals," Applied Clay Science, vol. 53, no. 4, pp. 723-728, 2011.

[20] M. N. G. James and G. J. B. Williams, "Structural studies of histamine RB effector molecules: the crystal structure of the antihistaminic drug (+)-chlorpheniramine maleate," Canadian Journal of Chemistry, vol. 30, pp. 1249-1257, 1974.

[21] C. J. Wang, Z. Li, W. T. Jiang, J. S. Jean, and C. C. Liu, "Cation exchange interaction between antibiotic ciprofloxacin and montmorillonite," Journal of Hazardous Materials, vol. 183, no. 1-3, pp. 309-314, 2010.

[22] Z. Li, H. Hong, L. Liao et al., "A mechanistic study of ciprofloxacin removal by kaolinite," Colloids and Surfaces B: Biointerfaces, vol. 88, no. 1, pp. 339-344, 2011.

[23] G. Blanchard, M. Maunaye, and G. Martin, "Removal of heavy metals from waters by means of natural zeolites," Water Research, vol. 18, no. 12, pp. 1501-1507, 1984.

[24] Y. S. Ho and G. McKay, "Sorption of dye from aqueous solution by peat," Chemical Engineering Journal, vol. 70, no. 2, pp. 115124, 1998.

[25] P. Trivedi and D. Vasudevan, "Spectroscopic investigation of ciprofloxacin speciation at the goethite-water interface," Environmental Science and Technology, vol. 41, no. 9, pp. 3153-3158, 2007.

[26] A. Jokic, A. I. Frenkel, and P. M. Huang, "Effect of light on birnessite catalysis of the Maillard reaction and its implication in humification," Canadian Journal of Soil Science, vol. 81, no. 3, pp. 277-283, 2001.

[27] R. M. McKenzie, "The surface charge on manganese dioxides," Australian Journal of Soil Research, vol. 19, no. 1, pp. 41-50, 1981.

[28] L. Aristilde, C. Marichal, J. Miehe-Brendlé, B. Lanson, and L. Charlet, "Interactions of oxytetracycline with a smectite clay: a spectroscopic study with molecular simulations," Environmental Science and Technology, vol. 44, no. 20, pp. 7839-7845, 2010. 

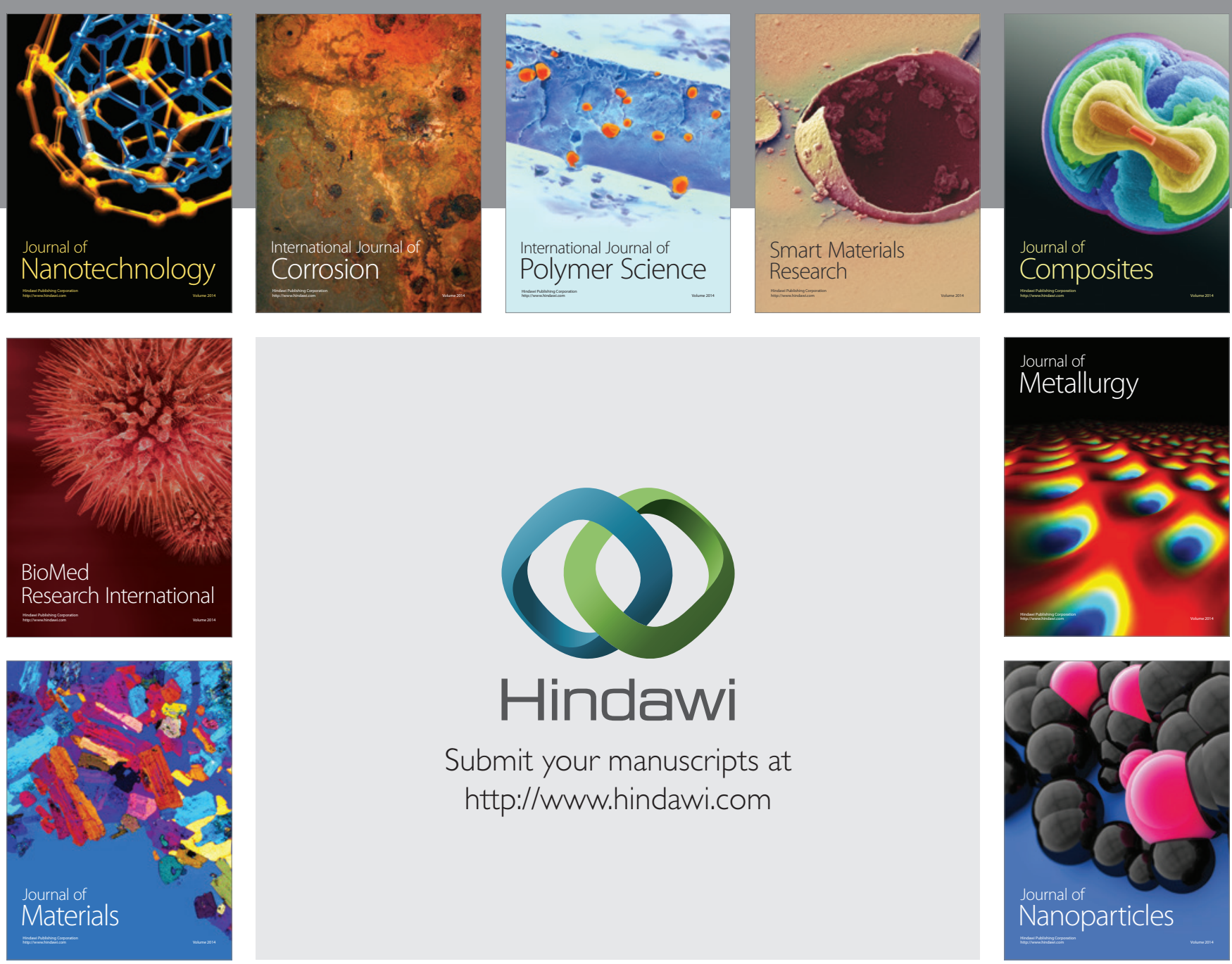

Submit your manuscripts at http://www.hindawi.com
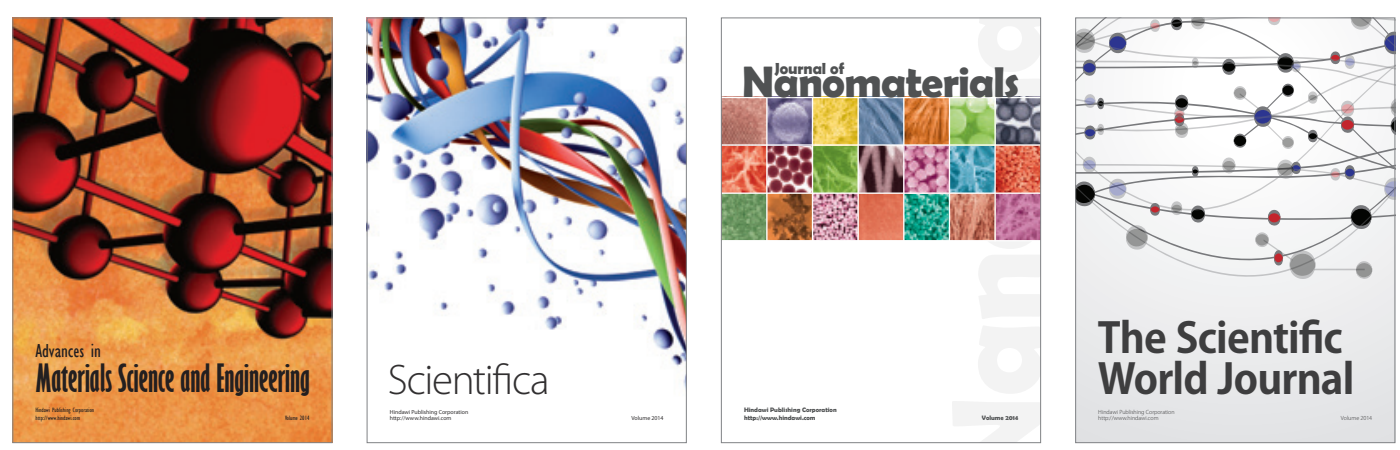

\section{The Scientific World Journal}
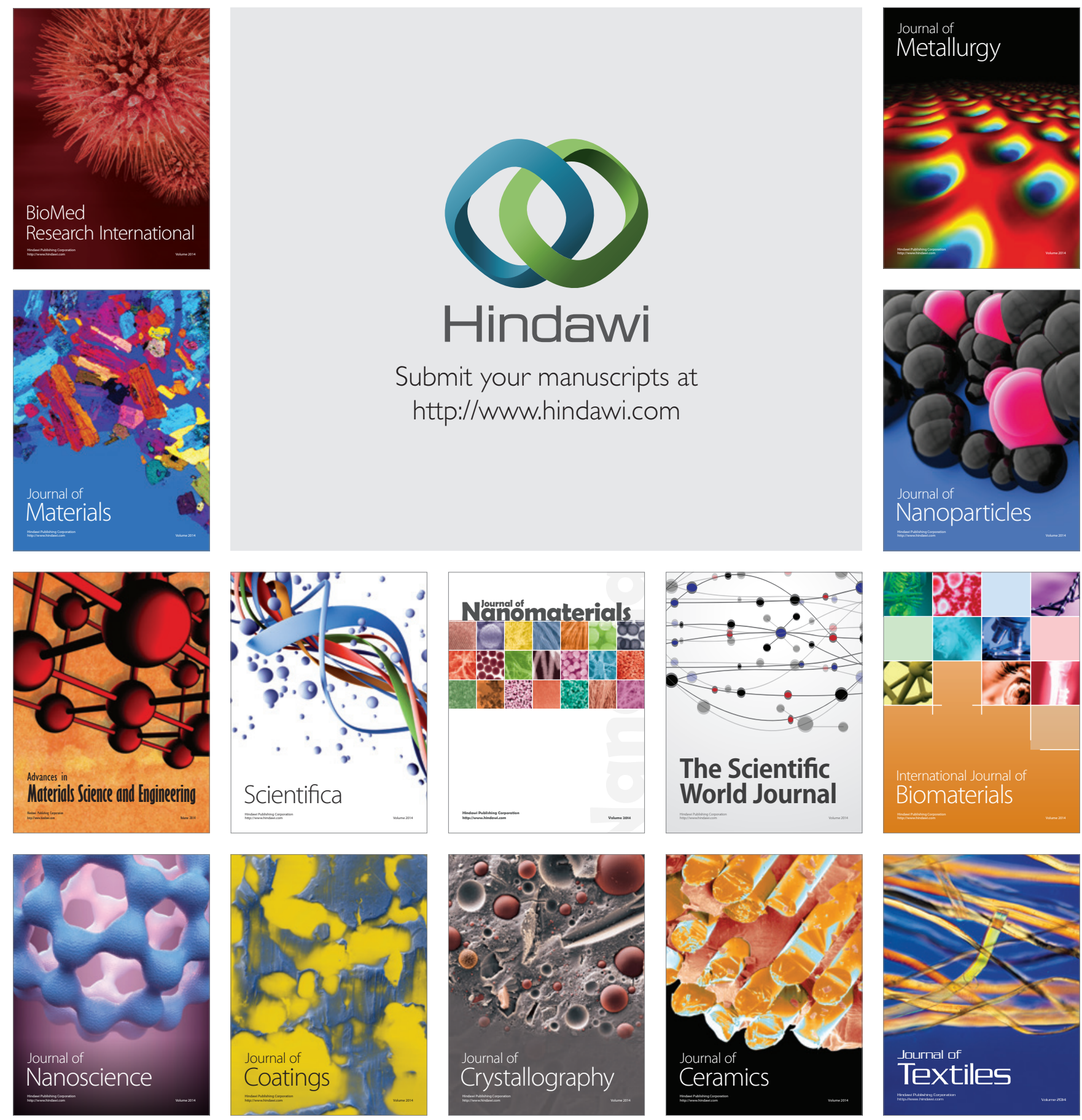